\title{
Close Reading: A Cornerstone of Text Appreciation in Advanced English
}

\author{
Sumei $\mathrm{Wu}$ \\ School of Foreign Languages, Sichuan University of Arts and Science, Dazhou, China
}

\begin{abstract}
Under the background of modern educational technology, Advanced English, a compulsory course for juniors or seniors of English majors in China, aiming to cultivate students' ability to comprehend and appreciate texts, is shifting from text-centered teaching model. Therefore, the present situation of Advanced English teaching is not optimistic. Importance and significance of close reading of texts should be confirmed and emphasized again in Advance English teaching and students should also be provided with guidance to their close reading of texts.
\end{abstract}

Index Terms - close reading, advanced English, text appreciation

\section{INTRODUCTION}

Advanced English, a compulsory course designated for juniors or seniors of English majors in China, aims to "cultivate students' ability to analyze and appreciate texts, think logically and independently through reading materials about politics, economy, society, language, literature, education and philosophy by distinguished authors" according to Teaching Syllabus for English Majors (2000, p.26). As an extended course of Elementary English, Advanced English is more challenging and difficult in diversity of text genres, profundity of contents and bulk of background knowledge. Therefore, some students more or less feel frustrated in their learning of this course. With the introduction of various teaching theories and approaches, great changes are taking place in the field of Advance English teaching. Traditional grammar -translation teaching model has been replaced by more advanced, more feasible and more effective teaching models. However, students' ability to analyze the text structure, discern the author's implication, appreciate the aesthetic values and think critically hasn't been greatly improved; on the contrary, they feel burdened by the heavy task of learning Advanced English. Effective learning cannot be achieved no matter how fancy and advanced the teaching models are if texts in the course books haven't been carefully and attentively examined. Recently, fast development in computer and internet technology brings fresh and salutary changes to teaching technology. In addition, teacher-centered teaching model in Advanced English has long been criticized. Teachers tend to adopt universally-acknowledged multimedia technology to Advanced English teaching. Pictures, audios and videos not only enrich the information, but also bring the pleasing shock to the students' hearing and sight, seemingly creating a very active and interesting class atmosphere. Even sometimes, in order to "make students actively involved in the class, some teachers abandon detailed study of texts and fill the whole class with question-answering, role-playing, video-watching or group-discussion under the fancy title of cooperative learning" (Qin, 2012, P.1). Although the whole class appears to be very active, very entertaining and very relaxing, after class most of the students will feel nothing in the mind. In fact, Advanced English learning without close reading of texts looks like a gorgeous building on a fragile foundation. Therefore, Advanced English course calls for teachers' and students' focus on texts. Texts are carriers of authors' ideas. Close reading of texts is a kind of experiential leaning, which will help students consciously discern real intention of texts and appreciate aesthetic values of texts, or they will fall victim to hearsay. This research will first go through origins and related knowledge of close reading, and then discusses the significance of close reading in Advance English, finally specific accesses to close reading of texts in Advanced English, in hope of helping students improve their performance in Advanced English learning and further their capability to appreciate literary works.

\section{Close Reading}

In the first half of the $20^{\text {th }}$ century, criticism in the west experienced a new turning point--- New Criticism which advocated close reading of texts. New Criticism first budded in Britain in the 1920s, and then matured in America in the 1940s and 1950s. New Criticism was assaulted by the schools of new formalism such as Stylistics and Narratology, and then it was regarded as backward and outdated by the criticism trend focusing on social-cultural contexts in the 1980s. In the 21th century, quite a few literary critics and scholars began to focus on literary texts; therefore, the trend of New Criticism based on close reading of texts regained attention and new development. The technique of close reading was pioneered by I. A. Richards and J. C. Ransome. In 1920s, Richards kept trying a very interesting experiment in his teaching. He asked his students to comment poems without giving authors' name, and to his great surprise, criticisms on every poem, even some written by famous poets, from the theme to the writing techniques, are quite different and even run contrary to one other. Hence, he thought a new critical approach should be created in order to promote readers' 
ability to understand and distinguish literary works. That is the origin of close reading. In 1921, a poetry journal named The Fugitive was edited by J. C. Ransome and his colleagues. Every poem was critically examined, and this proved to be very beneficial to poet in his later poetic creation. Although The Fugitive only existed for five years, but close reading developed in this period was inherited and gradually became the basic principle in New Criticism. Close reading then was technically developed by the New Critics of the mid-twentieth century, and so became the fundamental method of modern criticism. Close reading was developed further in the work of Professor Louise Rosenblatt. In French criticism, close reading is similar to explication de texte, the tradition of textual interpretation in literary study. From the perspective of New Criticism, a work of literary is treated as self-contained, self-referential and its interpretation is independent of readers and authors.

Since close reading in New Criticism was introduced into China, it immediately gained a lot of attention among Chinese scholars. YE Dang-qian (2009, P. 67-70) advocates that close reading of any literary works must adhere to the aesthetic principle, emotional principle and overall principle, and such strategies of close reading as breaking-sentence, exegetical study, commentaries and image can be employed in teaching of Chinese literature. CHEN Si-he (2004, p.109-116) discusses the significance and methods of close reading and holds that the relationship between close reading of texts and literary element of aesthetics should be valued in the academic community. XIN Ke-qing (2006, p.104-108) believes that the method of the combination of a close reading from the West and the traditional commentaries is a good access to a better comprehension of the text. CHEN Yan-li and MA Xiu-li (2010, p.75-78) hold that in the context of modern educational technology students' understanding of text through close reading together with teachers' necessary interpretation promote foreign literature teaching. ZHU Jian-Jun (2014, p.69-75) reviews the researches about close reading abroad and point outs that Close reading in the context of Curriculum is facing a lot of challenges and many concepts lack curriculum theory significance. Fu xiao (2014, p.56-61) makes an exploration to origins of close reading and its development in order to clear up misunderstanding and construct a literary approach which can bridge the west and China. Focus of Chinese scholars is more on adoption of close reading to teaching of Chinese literature and English literature; hence their researches are more concerned with significance and concrete strategies of close reading in teaching.

\section{SignificAnce of Close ReAding In ADVANCED ENGLISH COURSE}

One of the requirements for English majors in Advanced English course is to cultivate their ability to analyze, understand and appreciate texts. Traditional Advance English teaching is teacher-centered. In class, a text is often begun with the introduction to the author and the social context in which the text is produced, and then the teacher consciously or unconsciously conveys his or her interpretation of the text as something standardized to students. Therefore, under this teaching model, the student's understanding of the text is not the intention of the text itself, but the intention of the author or the social context. The imposing of the author's intention on the text is a typical example of "Intention Fallacy". At the same time, the teacher is also the reader of the text, so his or her interpretation of the text is only the representation of his intention. "Affective Fallacy" is thus committed. Everyone has different responses, understanding, attitudes, evaluation and appreciation of the same text based on their difference in life experiences, levels of knowledge, social-economical background and cognitive models. The most direct and simplest way to achieve personal and unique but closest-to-text experiential meanings of any text is to conduct a very careful, attentive examination of linguistic expressions, structures, symbols, rhetoric devices and styles in the text and try to figure out the meanings produced within the text. Therefore, Advanced English teaching based on close reading is not only necessary but also very important.

\section{A. Close Reading-A Countermeasure to "Superficial Reading" under the Influence of Modern Information Technology}

The world is hurtling into an interactive era, which is changing the way we communicate, study, work and entertain. In China, almost every college student is equipped with computers and smart phones, and their daily life and study are overwhelmed by Wechat, Weibo, QQ, readers, browsers, audio-players, video-players, Baidu, Google and so on. With a simple click on computers or smart phones, college students can be easily made accessible to mountains of information. Every day, information is updated at an unimaginable speed; college students tend to or are forced to acquire the information as quickly as possible. Gradually they fall into a habit of reading preferring pictures to words, digital text to paper text, amusement to knowledge, and fashion to classics. In this era of instant culture, college students are not patient enough to sit down, take a book, and enjoy themself in the magic world created by the author. "Superficial reading" is becoming a dominant reading model among the young people, which enables them to get the most information within the least time. Advanced English course is endowed with cultivating English majors' ability to understand and appreciate texts. The ability to understand and appreciate texts cannot be achieved through "superficial reading". The most popular set of course books for Advanced English course is known as Advanced English (book one and book two) edited by the late famous Chinese scholar ZHANG Hanxi in 1980, which was revised by WANG Lili in 2011. There are altogether thirty texts selected and excerpted from the most classical and influential works written by the distinguished authors in English-speaking countries. This set of course books offer a good opportunity for English majors to enjoy the beauty of English language, to gain an insight into politics, economy, culture and society, to learn 
something about the types of writing, figures of speech and text organization. Under the shock of modern information technology, English majors, especially in the study of this course, are expected to concentrate on texts, to treat the texts as something self-contained and self-referential, to dig out the meanings loaded in the texts, and then they can really improve their language abilities, deepen their understanding of English-speaking countries, to promote their trans-cultural abilities. Therefore, the call for close reading back to Advanced English class is a useful countermeasure to the habit of "Superficial Reading" dominant among English majors in the internet era.

\section{B. Close Reading --- An Access to Aesthetic Values of Texts}

Texts in Advanced English course books are selected and excerpted from the most influential and famous literary works. An approach of close reading to literary work satisfies the need of literary works as art. Art is a creation of human emotional symbols and excellent literary works are also human emotional symbols. Literary works are essence of human emotions and full of life. Research and exploration to literary works, on the one hand, rely on literary theories and literature reviews, on the other hand, require personal devotion of emotions. Researchers or readers are expected to feel, experience and comprehend through close reading of literary works. Advanced English course is entrusted with the task to guide the students to appreciate charms of literary classics, and to seek peace of mind and pleasure in reading literary classics, and to purge their soul and enhance their morality besides its task to improve English majors' language knowledge and language skills. In one word, Advanced English course aims to cultivate English majors' appreciative reading. As a higher level of reading comprehension, appreciative reading is an interactive and deep communion between the reading subjects (readers) and the reading objects (literary works). In order to realize emotional and spiritual communication with literary works, how to foster English majors' ability of aesthetic appreciation is a major concern that should be taken seriously. Reading based on quantity is one of the accesses to accumulation and cultivation of appreciative reading, but one's intuition to feel and appreciate aesthetic or artistic values loaded in literary works is acquired by his personal, attentive and close reading of works themselves. In traditional Advanced English teaching, the teacher's interpretation and appreciation of texts is revered as something standardized and authoritative, and students are more or less hinted or warned that following teachers' interpretation and appreciation could do well in the examination. Even sometimes one or two students' imaginative and unique sparkles would be ignored or dismissed because taking teachers as authority and model has long been the mind-set of some students in China. Something must be done to inspire students' appreciative and innovative ability. Students should be encouraged to conduct close reading of texts in Advanced English learning. Works or texts are carrier of ideas or thoughts. Authors' profound thoughts and historical and social values are coded in the artistic process of expression and the aesthetic form. Only through careful analysis of the artistic process and the aesthetic form, authors' intention and values can be discovered.

Close Reading, a critical approach and a reading model, can be employed in Advance English teaching to change the dominant "superficial reading" among English majors and help then to understand and appreciate artistic or aesthetic values loaded in the texts.

\section{Accesses to Close ReAding in Advanced English Course}

The reading subjects of texts in Advanced English are juniors and seniors of English majors who hope to cultivate their appreciative reading through the study of this course. The subjects of appreciation (also the reading subjects) tend to commit themselves to texts quietly and attentively, thrust themselves into the wonderful, magical, happy or melancholy world reconstructed by the language in the texts so as to seek spiritual comfort, express their emotion and purify their souls. Texts themselves should be their first and foremost concern. Such components as words, syntactic patterns, rhetoric devices, cohesive devices within texts coexist, inter-depend and interact not only to keep texts independent and intact, but also represent deep meanings that authors want to express. Close reading, not a kind of narrow formalism but a practical reading model to understand, interpret, appreciate and evaluate texts, even some obscure and unintelligible texts. Close reading is an effective way to acquire profound connotations through careful and attentive examining superficial structures of texts. Three accesses to close reading of texts in Advanced English course will be discussed as follows.

\section{A. Shift of Teachers'Role from Dominant to Guided or Collaborative}

Advanced English, as a compulsive course, plays a very important role in enhancing linguistic knowledge and skills, aesthetic appreciation, trans-cultural awareness and creative thinking of English majors. A course is completed by efforts made by both teachers and students. In traditional Advanced English teaching, teachers are dominant, authoritative and active. They design and monitor every teaching procedure, hoping to make the class teaching follow the so-called ideal and perfect pattern without taking students creative and independent ideas into their teaching plan. Today's Advanced English teaching seems to be drown in misdirection-close reading of words and structures are ignored because detailed analysis of words and structure is what Elementary English should deal with and Advanced English class should deal with something more profound, more abstract and more ambiguous such as theme, significance, enlightenment of texts. Therefore, in their class, introduction of authors' life story, social background and other works of authors are foregrounded, and they consciously or unconsciously convey their interpretation and appreciation of texts to students. Students' creative and unique understanding and appreciation of texts which derive 
from their repeated close reading of texts are killed by this kind of teaching model. Teachers of Advanced English are expected to study texts, frame the understanding of texts, develop close reading strategies, and then lead students to close reading of texts.

We cannot be from one extreme to another, so the role of teachers in Advanced English is requisite. Students' close reading of texts cannot be achieved at one stroke. From teachers' dominant model to teachers' guided/ collaborative model to students' independent model, step by step, students' ability to conduct close reading of texts can be stimulated and improved. The ultimate goal of close reading of texts is that students consciously and independently decode texts, understand meanings and obtain aesthetic values. The role of teachers is directed to design close reading procedures, evaluate students' close reading.

\section{B. Close Reading of Language in Text}

Usually, students may have difficulties in close reading of a long text-a long passage or a book. Texts in Advanced English books are worthy of close reading because they are appropriate in length and prominent in artistic or aesthetic value. To English majors, English learning more or less is entrusted with learning new words and expressions; hence focus on words is part of their English learning. In the literature world, every reality is established by words, and every word is endowed with some spiritual quality that not only can go into authors' heart, but also make readers introspect, realizing individual's communication with outside world. It goes without saying that words, as the basic unit of writing, carry weight in creation of literature world. During close reading of texts, choice of words or diction, connotation and denotation of words, impact of words, repetition of words, figures of speech in words and so on should be examined and explored carefully and seriously. In this way can meaning of texts be figured out and understood reasonably. Face to Face with Hurricane Camille (Advance English ,Book one), it tells about John Koshak's struggle against natural catastrophe Hurricane Camille. A cluster of verbs with the monophthong [æ] are employed in the narration, such as "lash, crack, slashing, smash, shatter, rampage and lap". When the monophthong [æ] is pronounced, it will give people a sense of urgency and discord. The association between sound and meaning is better realized in context, and one after another verb with the monophthong [ æ] vividly creates massive and continuous destruction, like a whip that is striking one after another reader's body, thrusting them in the real situation to feel life and death struggle in front of the deteriorating Hurricane Camille. What's more, in the critical moment, the author cleverly chooses a set of monophthong verb such as "lash, lap, skim, scud, yell, dump, shot, snap, hit and whip", which are concise and clear, rhythmic and forceful. Meantime, monophthong verbs are stressed, all of these stressed verbs go through the whole narration, building an atmosphere of hurry, tension, suspense so as to reveal that Sherlock's family facing the approach of death fight against Hurricane Camille courageously and tenaciously.

\section{Close Reading of Structures in the Text}

Focus on such linguistic forms as words, phrases and sentence in the text is not quite enough to achieve real understanding and appreciation of any text, and text-designing above lexical level also deserves careful examination. Students should be guided to figure out clever design of text, characterization, arrangement of paragraphs, environmental description and so on. All of these together with language expressions contribute to theme or central idea that the author wants to convey. For example, The Loons (Advance English, Book two), written by the distinguished Canadian female writer Margaret Laurence, tells of the plight of Piquette Tonnerre, a girl from a native Indian family. Her people were marginalized by the white-dominating society. They were unable to exist independently in a respectable, decent and dignified way and impossible to fit into the main currents of culture and difficult to be assimilated comfortably. At school, the girl Piquette felt out of place and ill at ease with the white children. When she had grown up she didn't have any chance to improve her life. In fact her situation became more and more messed up. In the end she was killed in a fire. At the beginning of the story is a detailed description of the scenery, which not only gives a clear account of where the story takes place, but also contains some vague accounts of the defeat that Metis, half breeds of French and Indian, experienced in their fight against white people. Dirty and messy living conditions and being in the lower and oppressed class from the start imply the tragic fate of Piquette. In addition, two scenic descriptions of summer house by Diamond Lake which is the habitat of the loons also highlights of the story. On that specific summer, everything around the summer house by Diamond Lake is so good: "spruce, raspberry, moss, wild strawberry, white flower, squirrel, antler, fragrant breath, sparkling water", a free kingdom for Vannisa and a habitat for loons. The beautiful natural view forms a sharp contrast with the modern atmosphere of the diamond lake at the end of the story: "a flourishing resort-hotels, a dance-hall, cafes with neon signs, the penetrating odours of potato chips and hot dogs, which implies that the loons have to fly away or just die because their natural habitat has already been destroyed by the human civilization. The clever arrangement of a parallel between Piquette and loons indicates that the fate of loons symbolizes the tragic ending of Piquette, as a Metis, who cannot be assimilated comfortably into white-dominating society. In despair, death may be the only alternative left to her.

Analysis of text-designing above lexical level can help students achieve a better understanding and appreciation of texts. However, all of these can only be accomplished by close reading of texts.

\section{Close Reading, not Closed Reading}

Close reading had ever been mistaken for closed reading in China for quite a long time. One of the reasons is that 
“ when close reading was first introduced into China, it was wrongly translated into “封闭阅读” (closed reading)” (ZHANG, 2015, p.10-13). In addition, literary critics in China has long followed the model of literary criticism based on ideology which involves such procedures as historical background, author's life stories, contents of works and artistic features, and they want to avoid disadvantages of this ideology-based literary criticism and with the new critical approach — close reading they could focus on the text itself and assess the text objectively and independently. Hence, to some of them, close reading became “封闭阅读” (closed reading). In fact, from its theories and critical practices, New Criticism is not diametrically limited within the text. The distinguished master of literary criticism, Rene, Wellek (1981) holds that New Criticism has always adopted an almost utterly historical outline in its literary studies; strong historical sense is revealed at all times. Close reading in New Criticism doesn't completely run contrary to other literary criticisms which focus on history, culture and politics, and it aims to discover paradox, irony, ambiguity, tension in the analysis of literary works and finally achieve the balance of various conflicts.

Close reading of literary works isn't equal to "closed reading” or "detail reading". In Advanced English teaching, careful examination of texts plus enough attention to their contexts can ensure a better understanding and appreciation of texts. This method is also called "overall close reading" advocated by Shen Dan (2008, p.1-6) which can reveal a hidden subtext cloaked in the surface text. Students are encouraged to take into comprehensive consideration various components of texts, relate texts to their contexts, and employ intertextuality researches into the target texts and their related texts.

\section{CONCLusion}

In one word, close reading of texts in Advanced English can make students accessible to artistic and aesthetic world reconstructed by language. Based on text itself, reading subjects (appreciating subjects) could experience and enjoy the moment of subtle beauty, purge their spirits, gain an intuitive insight, and discern the intention of texts. It is especially necessary to improve superficial reading" cultivated in information era among young people. Close reading, from a critical approach, a reading approach in the past to a teaching model, is facing many challenges, issues, questions, and its concept, curriculum planning and pursuit is becoming gradually clear. However, the study on close reading is not optimistic, many concepts lack curriculum theory significance. This research of employing close reading into Advanced English teaching is a very preliminary attempt in the hope of throwing out a minnow to catch a whale. More teachers and scholar are expected to carry out more researches into close reading in the context of Curriculum.

\section{REFERENCES}

[1] Chen, S. H. (2004). The Significance and Methods of Close Reading in the Present Era. Hebei Academic Journal, (2): 109-116.

[2] Chen,Y. L., \& M, X.L. (2010). "Illustration" and "Close Reading" under the Background of Modern Educational Technology. Journal of Hebei Normal University of Science \& Technology, (1): 75-78.

[3] Foreign Language Teaching Advisory Board under Ministry of Education. (2000). Teaching Syllabus for English Majors, Beijing: Foreign Language Teaching and Research Press.

[4] FU, X. (2014). Origin of Close Reading. Journal of Chongqing University of Education, (2): 56-61.

[5] QING, X.B. (2012). Alert to the Entertainment of Curriculum. Contemporary Foreign Language Studies, (7):1-2.

[6] SHEN, D. (2008). "Overall Close Reading" and Reinterpretation of Short fiction. Journal of Sichuan International Studies University, (1):1-6.

[7] Wellek, Rene. (1981). A History of Modern Criticism 1750-1950. 8 vols. Cambridge: Cambridge University Press, 1981.

[8] XIN, K.Q. (2006). On the Method of Close Reading in Literature Teaching. Journal of Teachers College Qingdao University, (3):104-108.

[9] YE, D.Q. (2009). On the Teaching Method of Close Reading. Journal of Anqing Teachers College, (6): 67-70.

[10] ZHANG, H. (2015). From the "Closed Reading" to "Perception"-The Misreading of the "Close Reading" in China. Research of Chinese Literature, (2):10-13.

[11] ZHU, J.J. (2014) Foreign Close reading: Theory, Curriculum, Content, and Enlightenment. Journal of Urumqi Vocational University. (1):69-75.

Sumei Wu is currently a lecturer at School of Foreign Languages, Sichuan University of Arts and Science in China. She got her MA degree in English language and literature from Chongqing Normal University in 2010 and her research interests cover Functional Stylistics, language education and literary studies. She has published more than 10 papers in Chinese academic journals and responsible for two research programs. 